\title{
Traducir desde enclaves transnacionales: algunas reservas críticas
}

\author{
FÉLIX MARTÍN GUTIÉRREZ \\ Universidad Complutense de Madrid \\ felmar@filol.ucm.es
}

Recibido: 14 de febrero de 2013

Aceptado: 15 de abril de 2013

\section{RESUMEN}

Este trabajo intenta examinar varias implicaciones culturales, lingüísticas e ideológicas derivadas de la influencia de los estudios postcoloniales en la traducción. Específicamente muestra varias reservas, especialmente a quien no comparta un acercamiento constructivista, sobre las alternativas que la apertura transnacional viene planteando en el tratamiento político de la traducción, en la interpretación cultural de lo que se considera no traducible o propio de su inconmensurabilidad y en la utilización crítica de la hibridación. Como preludio de este escenario transnacional el trabajo recoge algunas opciones históricas que permiten ver cómo se ha llegado hasta aquí, opciones relativas al alcance de la lengua inglesa en el contexto de la globalización, la cautelas que suscitó la incidencia intercultural en la traducción y la expansión del fenómeno de la traducción en la actualidad.

Palabras clave: Traducción, estudios Postcoloniales, transnacional, hibridación, ideología.

Transnational translations: some doubts and perplexities

\begin{abstract}
This paper tries to examine some cultural, linguistic, and ideological implications brought about by the impact of postcolonial studies in translation theory and practice. These implications may cause some perplexity when viewed from perspectives which do not share a full constructivist approach and are mainly concerned with the political turn of translation practices and institutional politics, the cultural interpretation of potential and unexplored spaces of translation, and the critical use of hybridity. As a prelude to these issues the essay provides a historical review of the ideological development of the English language in the context of globalization, as well as the intercultural options faced by translation and its present transcultural expansion.
\end{abstract}

Keywords: Translation, Postcolonial Studies, transnational, hybridity, ideology. 
Sumario: 1. Introducción. 2. Entornos globalizados de la lengua inglesa. 3. Cautelas ideológicas sobre la vía intercultural dela traducción. 4. Modalidades textuales y procedimientos críticos de signo transnacional.

\section{Introducción}

Hemos escuchado durante bastante tiempo la cantinela de que la traducción debía superar ciertos complejos de inferioridad y tomar más en serio su supuesto carácter instrumental. $\mathrm{O}$, si queremos, revalorizar o justipreciar tanto la teoría como la práctica, pues una pretende aspirar al olimpo del pensamiento crítico y la otra rebajarse al mercadeo de las comunicaciones multiculturales. No ha sido la traducción una actividad muy consciente de esta situación, ni ha codiciado derechos o territorios que no la hayan venido como por sorteo o compensación profesional. Aun sacudida por algunas incursiones teóricas radicales e innovadoras de Derrida (2001), Spivak (1999), Bhabha (1994), Venuti (1998), Damrosch (2009) o Even-Zohar (2006) la realidad es que puede seguir flirteando con numerosas áreas científicas y humanísticas ya afiliadas y a la vez dispersarse por las rutas entrecruzadas de la globalización Muchos traductores profesionales y académicos se encuentran ante tal proliferación de áreas, campos científicos, zonas de relaciones e influencias lingüísticas y culturales, tal desbordamiento de métodos, proyectos e intereses que no les preocupa tanto diagnosticar este fenómeno cuanto responder concretamente a sus predilecciones intelectuales. Tal vez pocas veces la dispersión, la comunicación intercultural, las variedades inter-lingüísticas, o la conectividad tecnológica y funcional habían propiciado un mapa tan estimulante y comprometido con la función esencial de la traducción -relacionar, comparar, trasladar, transformar, interpretar, manipular- y con su justificación social, cultural o política. Digamos que la traducción ha entrado en una órbita de la comunicación realmente vertiginosa y que más que redefinir sus funciones procede discriminar selectivamente entre múltiples itinerarios.

Esta realidad refrenda ese salto cualitativo que hace años emprendió al dejar atrás la obsesión por la equivalencia de palabras o textos, o de dos lenguas, cual si de un diccionario bilingüe se tratara, y convertirse en una investigación epistemológicamente compleja y culturalmente motivada. Este salto puso de relieve las alternativas que podrían orientar al fenómeno de la traducción y proseguir unos objetivos cada vez más clarificadores, aunque la imposibilidad de la traducción siga constituyendo un aperitivo teórico ofrecido por Walter Benjamin, degustado por numerosos discípulos y aireado por no pocos especuladores. Precisamente mientras crecen las conjeturas y el idealismo pedagógico en torno a si esos márgenes de lo imposible se ensanchan, o su perfil analógico se detecta en zonas híbridas, o su tejido verbal emite signos transculturales, una mirada atenta a las teorías lingüísticas de las equivalencias no lleva muy lejos, según Anthony Pym. De hecho podemos anotar su observación de que normalmente "dudamos sobre si el término equivalente es igual a una posición o a un valor dentro del lenguaje, o un mensaje, o un texto con conte- 
nido y estilo, o todas esas cosas a la vez pero cosas en tiempos distintos" y proponerla como pauta para cualquier traductor o lector que se aventure en esta empresa o desee realizar un recorrido por sus últimas décadas. $\mathrm{O}$, cómo no, si martes y trece connota mala suerte en español y en Taiwan prefieren "el viernes trece", por razones de invasión cinematográfica, podrá hablarse, deduce Anthony Pym, de equivalencia natural si a lo que se refiere el lenguaje es anterior a la intervención del traductor y de equivalencia direccional si se refiere a lo que los traductores pueden hacer con el lenguaje (Pym 2007: 277-8). Pero esto es mera suposición de una interpretación basada en la semejanza. La equivalencia es pura ilusión.

Desde el panorama abierto por estos itinerarios puede el traductor entrever cómo se suceden metodologías y planteamientos teóricos que acompasan a veces febrilmente la lógica crítica y cultural de la globalización y de sus zonas más transnacionales. De seguir la secuencia trazada por la globalización en los estudios de traducción es preciso no olvidar cómo la entrada en los dominios transnacionales ha sido consecuencia lógica del post-colonialismo, de su efecto cultural nivelador y democratizador, de la dialéctica cultural desarrollada entre la presión externa colonizadora y la precaria situación local. Si la lógica del post-colonialismo puede guiar un recorrido por el mapa transnacional es conveniente empezar a leer este mapa por la vertiente propia de la traducción como proceso de mediación, comunicación e intervención lingüística. Parece adecuado presuponer con Gayatri C.Spivak alguna estrategia de "descolonización de la mente" en términos del poder, hegemonía y evolución de la lengua en las zonas colonizadas. No requiere justificación alguna este enclave inicial, archiconocido en los estudios sobre la historia del inglés como lengua franca e indisolublemente ligado a los procesos de globalización. No por repetida la versión más examinada a este respecto es la que sospecha de que la globalización del inglés ha ramificado sus centros de influencia en territorios que desde la periferia presentían un cambio de modelo lingüístico global, una organización policéntrica efectiva y más diferenciada del dominio británico o norteamericano. Por ello reconstruimos algunas alternativas de esta historia a partir de los efectos de la globalización y de los riesgos de la traducción en ámbitos "localizados".

\section{Entornos globalizados de la lengua inglesa}

Suelen los sociolingüistas iniciar la cronología del inglés como lengua franca a partir de los años cincuenta del siglo XX, aunque la historia de esta lengua haya registrado tantas metamorfosis institucionales, sociales, políticas y religiosas que no se entiende muy bien cuándo pudo haber dejado de ser franca e internacional. Es este un espectáculo que no se contempló de forma acusada hasta que el nacimiento de los estudios ingleses en los años veinte introdujo su estudio en la universidad, el New Bolt Report instó su institucionalización y los pedagogos de la escuela de Cambridge la supeditaron al estudio de la literatura. La historia secreta de los estudios ingleses ha desvelado momentos cruciales de la orientación social y política del inglés como lengua franca a comienzos de siglo XX, de su enseñanza e inculcación pedagógica estrechamente ligadas a la imagen y al poder del Imperio Victoriano, 
con mayúsculas. La constelación ideológica victoriana aparece articulada, entre otros factores, por la glorificación de un Shakespeare proto-imperialista, -genio de la raza, el mejor exponente del carácter británico,- la afirmación de las tesis darwinistas sobre etnografía y su expresión lingüística, el encumbramiento de la raza sajona (la gran familia teutona), la difusión de la pedagogía cultural de Mathew Arnold, equilibrista y moralmente depuradora, la sacralización de la función profesoral en Canadá, Australia, la India y otros países de la Commonwealth y hasta en Estados Unidos, en donde el currículo docente que diseñara Franklin en 1751 quedaría relegado a un segundo plano. Obsérvese que su Autobiografía da testimonio de un dominio lingüístico excelente y que en ella la lengua inglesa aparece iconográficamente en un pedestal sagrado, sentada a la derecha del Conocimiento.

Alusiones como éstas podrían enriquecer la historia de un proceso cultural y lingüístico inevitablemente ligado a las políticas coloniales británicas y a la expansión de su imperio. No pretenden estas referencias componer un anecdotario para recrear los avatares de la historia de la lengua inglesa, sino una arqueología imprescindible de los estratos culturales, sociales y políticos que han cimentado unas ideas de lengua franca todavía libre de la dialéctica inherente a la globalización. Por ejemplo, nos dicen Ivor Goodson y Peter Medway (1990: X), que el inglés constituyó un verdadero campo de batalla ideológico en Canadá, Australia, África del Sur y América, que jugó un papel fundamental en la formación de la identidad nacional e imperial, -sin duda filtrando los rasgos idealizados del carácter inglés- o que su enseñanza en las escuelas garantizó un dominio lingüístico no exento de discriminación frente a otra lenguas. No deja de asombrar que la identidad nacional y la personal imbricadas en la enseñanza parezcan cara y cruz de una misma moneda. Según Robert Morgan (1999:205-8), el inglés como materia docente comenzó a enseñarse antes en las colonias que en las escuelas de secundaria en Inglaterra y varias ciudades importantes canalizaron el mercado cultural del imperio. Concretamente en Canadá la sistematización y popularización de la lengua y de la literatura constituyeron una empresa cultural de primer orden, empresa desplegada activamente a principios del siglo XX. El estudio sistemático de la lengua encontraría signos rituales de enaltecimiento patriótico en fecha tan señalada como el día del Imperio, episodio emblemático de una politización que alcanzaría cotas inimaginables al resonar en los círculos más familiares y recónditos del país. La fertilidad de clichés en este terreno no pudo ser más determinante: la visión de Inglaterra como maestra de escuela, la celebración del carácter inglés, la exaltación moral y civilizadora de la literatura inglesa y de la lengua, la reciprocidad e identificación de rasgos étnicos y culturales entre canadienses e ingleses, en suma, la entronización de la lengua, la cultura y la literatura inglesas como algo esencial para la consolidación del poder y del progreso (Morgan 1990:206).

No es necesario reconstruir una historia harto conocida y sobrecargada ideológicamente cada vez que reaparecen los fantasmas del monopolio lingüístico del inglés y sus círculos expansivos y globalizados. Puede pensarse, como observa Martin A. Kayman (2004:2-4), que en nuestros días el término lengua franca no remite directamente a un pasado político nacionalista o imperialista, o que los vestigios de ese pasado no significan nada para los hablantes de la lengua franca actual, es decir, que 
en cierto modo la historia en cuanto presencia continuada de relaciones de poder no ejerce función real en esos países y que por lo tanto ha desaparecido. ¿Realmente, nos preguntamos, la lengua inglesa se ha desligado del imperio" (Inglaterra) y el poder (imperio) de la lengua ha roto con la madre patria? Este doble proceso -ingeniosamente formulado por Martin A. Kayman (2004:2) como contraposición entre "the kingdom of language and the language of kingdoms"- no es un mero juego de palabras. El propio Kayman proporciona una historia social de la formación ideológica del inglés como lengua franca que, aunque aparezca actualmente como algo neutro políticamente y lingüísticamente autónomo, remite expresamente a hechos y momentos históricos concretos, a la evolución filológica del inglés, a la política educativa británica, a la historiografía textual y literaria, a su implantación oficial como "lengua franca".

Ciertamente dentro de esta historia cabe situar la propuesta del inglés como lengua franca a raíz de los acontecimientos que David Crystal refiere en English as a Global Language (1997) y que se concentran en la década de los cincuenta. Fue la encrucijada política y cultural de la Guerra Fría, efectivamente, un período crucial para el reconocimiento del inglés como vehículo de comunicación internacional, rubricado en la creación de la UNESCO, LA UNICEF (1946), el Banco Mundial (1946), la Organización Mundial de la Salud (1948), la Agencia de Energía Atómica y otras instituciones. Ni que decir tiene que la instrumentalización del inglés llevada a cabo en estas instituciones reforzó la pedagogía lingüística norteamericana de la posguerra, abierta a nuevas metodologías en la enseñanza del lenguaje (básicamente fieles al funcionalismo de Leonard Bloomfield y Charles C. Fries) y al estímulo de las prácticas textuales implantadas en las aulas por los maestros del "new criticism".

No es posible esbozar esta genealogía institucional sin resaltar precisamente el impacto de esa otra constelación cultural y lingüística que popular o despectivamente llamamos americanización y que configura en la actualidad los enclaves transnacionales más frecuentados. Sucede, efectivamente, que este fenómeno ha desbordado los cauces de su propia articulación y descripción, por lo que la recuperación de su historia debe acompasar cualquier predicción futurista y la ponderación de sus efectos concretos e históricos alertar sobre su transformación. Si la paradoja cultural que Martin A. Kayman destaca en su recorrido por la historia de la lengua inglesa no puede desentrañar la creciente hegemonía del inglés y sus circuitos de globalización, el horizonte norteamericano presenta itinerarios transnacionales demarcados por el poder económico y cultural, como sugirió Pierre Bourdieu. De nuevo constatamos aquí la contradicción palpable entre autonomía lingüística y trayectoria ideológica. A decir de Juliane House (2003: 558) la lengua franca no es ni anglo ni americana, sino híbrida y negociable, una atribución que de ningún modo neutraliza descriptivamente su carga cultural o razón ideológica. Para alguien tan sensible a los problemas de la política lingüística internacional como Robert Phillipson no es concebible tal reduccionismo o miopía cultural. Es el imperio norteamericano y su poderosa maquinaria tecnológica -televisión, cine, editoriales, redes virtuales, internet- lo que abre o cierra las compuertas transnacionales. Como recoge en "Lingua franca or lingua frankensteiniana? English in European integration 
and globalization" (2008:4) la asimetría entre el porcentaje de películas americanas proyectadas en Europa y las europeas en América es escandaloso, como lo es la retórica de liderazgo global que a veces proclaman. Las persistentes alusiones de este crítico a la política norteamericana y a su alianza con Gran Bretaña, incluidas declaraciones de los presidentes, no rebajan un ápice el tono de su fuerza argumentativa. Forma ya parte de un credo miméticamente recitado recordar las premisas y estrategias del imperialismo cultural y mencionar cómo ha sido objetivo político y económico de los Estados Unidos garantizar que el mundo caminara hacia una lengua común y que la tecnología garantizara una seguridad y calidad de vida específicamente americanas.

Al contraponer presente y pasado, razón ideológica y autonomía lingüística, construcción cultural y herencia histórica pretendemos situarnos en aquellos enclaves transnacionales de la traducción que se ven afectados por el impacto de la globalización. La aproximación a la lengua franca requiere inicialmente una recomposición de los nuevos escenarios comunitarios, regionales, nacionales o transnacionales de hablantes, es decir de la geografía de variantes lingüísticas que configurarían un mapa geo-lingüístico esencialmente cambiante y dinámico. Su configuración social, lingüística, política y cultural" se alimenta al fin y al cabo de la pluralidad de interacciones que exhiben otras modalidades o variantes dentro de su esfera transnacional. Actualmente comprende tal diversidad lingüística y cultural, tal pluralidad de normas, de centros geográficos, de competencias comunicativas y prácticas que no puede ceñirse formalmente a criterios o espacios empíricos determinados o a rasgos léxico-gramaticales comunes. Por enfatizar esta realidad recordamos con Juliane House, que probablemente no es "una lengua nacional, sino un mero instrumento carente de capital cultural colectivo, no es tampoco una lengua útil para designar la identidad....y no existe un grupo de hablantes de la lengua franca definibles (House 2003:560)". Su carácter instrumental plantea tal vez conflictos con las lenguas locales o puede generar diglosias, dificultar la traducción o desvelar la complejidad cultural y lingüística que trajo consigo el cambio de paradigma: desequilibrio entre hablantes nativos y no nativos, imposibilidad de reclamar derechos exclusivos de propiedad sobre la lengua por parte de los nativos, eliminación de hecho de discriminación procedente de estos términos, o desligar su cultura de la anglosajona. Dada la diversidad de este medio comunicativo, sugieren algunos especialistas, su construcción es intersubjetiva para cada contexto específico de interacción, su forma es negociada por cada grupo de hablantes para sus objetivos concretos, por lo que resulta muy difícil describirla a priori.

Es imaginable, por ello, que la globalización siga generando avalancha de reacciones y actitudes encontradas en torno a esta situación, generalmente suscitadas por sus nuevos escenarios postcoloniales y transnacionales. Por un lado la expansión del inglés continúa amenazando la diversidad lingüística con fuerza depredadora, mientras que por otro permite a todos los ciudadanos del mundo comunicarse de forma libre. Esta polarización, agriamente recorrida durante varias décadas, sigue generando nuevas versiones, perpetuando para unos la herencia de un imperialismo mono-cultural, o alentando en otros la visión cosmopolita que acabaría con la Babelia actual eliminando las barreras lingüísticas. A raíz de la publicación de Global 
transformations: politics, economics and culture (1999) se contempla una opción intermedia que arbitre entre las dos posiciones extremas, es decir entre la que sostienen los "escépticos" y la de los defensores de la globalización. Frente a quienes creen que la globalización refleja niveles de interdependencia ya conocidos en otros períodos y que por lo tanto es un mito, pues continuará controlada por los gobiernos nacionales, o quienes tienen fe ciega en la capacidad homogeneizadora de las redes transnacionales y sus efectos en los dominios económico, social, político y cultural (o si queremos en el magnetismo de la cultura popular americana y el consumismo occidental), los partidarios de una alternativa intermedia o transformadora aceptarían la globalización como un revulsivo eficaz para conseguir cambios de largo alcance (Dewey 2007:335-338). Referida esta última opción al ámbito lingüístico, cobrarían una importancia capital la incontenible diversidad lingüística, la posibilidad de crear un sistema supra-normativo para la enseñanza del inglés internacional, a la par que proporcionar modalidades específicas para diferentes comunidades, regiones o naciones.

La traducción en el marco de la globalización del inglés es presa de dificultades estratégicas. Evidentemente su expansión afecta directamente a las relaciones esenciales y a múltiples campos de la producción, circulación y recepción de los procesos inter-lingüísticos y culturales, tal vez miméticamente reforzando la reproducción de algunas formas o "commodities", o inconsciente de los efectos diferenciadores que crean los mercados, la hibridación o la dispersión lingüística en las fronteras transnacionales. Frente a los estudios de carácter sociológico, político, económico o cultural sobre las alternativas transnacionales -que en general han prestado poca atención a los problemas del lenguaje- o los estudios de lingüística aplicada, la traducción se ve en la necesidad de justificar su función cultural entre los espacios cambiantes y migratorios de estas alternativas. ¿Cómo captar, por ejemplo, el impacto de la globalización en términos de factores del lenguaje y de su impacto en la comunicación y en la traducción? ¿Cómo reconocer lo que es central o periférico en el marco de una interconexión lingüística y cultural cada vez más consolidada? $\mathrm{Si}$, como sugiere Blommaert, no se globaliza una lengua abstracta, sino formas especificas del habla, géneros, estilos y formas de práctica literaria, ¿nos sirven las nociones convencionales de lenguaje y de variedad lingüística? Y ¿qué registros lingüísticos ensaya la traducción en este escenario?

Estas últimas preguntas abordarían de hecho el punto de llegada de cualquier reflexión sobre el impacto de la globalización en la traducción de la lengua inglesa. Más que calcular las dimensiones del nuevo mapa lingüístico internacional producido por la globalización, interesa a estas alturas, como sugieren Barabara Seidlhofer y Jennifer Jenkins (2003:141), ver cómo se conceptualiza el "ingles" a partir de una política lingüística nueva, iniciativa que estas dos especialistas pretender llevar a cabo en términos empíricos, elaborando un corpus que recoja el uso del inglés entre hablantes no nativos para poder redefinir e identificar lo que se postula como "lingua franca (ELF)". La elaboración de un mapa geo-lingüístico se antoja imprescindible para atenerse a criterios empíricos, no sólo para explorar cultural y lingüísticamente el ámbito de la lengua franca, sino para acercarnos a la diversidad y pluralidad que han acogido también los términos "Global English/es", "World English/es". 
A tal efecto los corpora ELFA (English as a Lingua Franca in Academic Settings, Mauranen, 1993), VOICE (The Vienna Oxford International Corpus of English)', NL (English as a Native Language) o ICE (International Corpus of English) constituyen una primera muestra sociolingüística indispensable para detectar las fuerzas de hibridación, ya sean de signo homogéneo u heterogéneo. Mas como es de esperar las fuerzas centrípetas que genera la diversidad lingüística suponen un riesgo para el significado del inglés, más que para su forma, una cautela que Allan James llegaría a repetir advirtiendo cómo ni la defensa de las culturas y de las lenguas nacionales, ni la descripción de una lengua franca, ni siquiera la concentración en una ingles plural plantean adecuadamente la diversidad del significado (James 2009:83).

Es incuestionable que, como auguró David Graddot (2006:14) hace pocos años, entre el 2010 y el 2015, un tercio de la humanidad aprenderá inglés, lo que añadido al billón que ya lo habla, supone que la mitad de la población mundial se comunicará en esta lengua. A la luz de la creciente introducción del inglés en los currícula de los centros de enseñanza primaria por todo el mundo la predicción de Graddot puede cumplirse. Veríamos entonces cómo efectivamente el inglés no sería simplemente una destreza básica, sino un requisito imprescindible para realizar actividades cotidianas y cometidos profesionales, por lo que la diseminación de la traducción por contextos transnacionales será espectacular. Los cálculos vienen a corroborar la suerte de algunas predicciones emitidas hace varias décadas y a aventurar, como lo hace Martin Dewy (2007:350), que tal vez no ha existido un caso igual en la historia de la humanidad, pues las dimensiones de su difusión geográfica, la diversidad cultural de su hablantes, los dominios casi infinitos en los que se asienta, así como los objetivos a los que responde, así lo dan a entender. Lógicamente la interconexión de los dominios culturales, sociales, políticos y económicos que presenta el mundo actual puede justificar una valoración de esta naturaleza.

\section{Cautelas ideológicas sobre la vía intercultural de la traducción}

Periódicamente se emiten predicciones espectaculares sobre un futuro globalizado que a la vez que ponen en evidencia el optimismo de quienes ven en la globalización una especie de panacea universal ciegan nuestra capacidad perceptiva o coartan la posibilidad de actuar consecuentemente. Nada más inoportuno en el caso del inglés que seguir proyectando ciertos delirios de grandeza derivados de épocas de la colonización y que reviven espontáneamente cada vez que se constata la marcha implacable de la revolución tecnológica, se reclama una homogeneidad cultural para millones de hablantes no nativos o se inyectan los valores culturales dominantes en los textos de enseñanza de la lengua. Precisamente la deuda pendiente que ha generado la globalización tiene que ver con la pérdida de identidad cultural, no sólo con la sospecha, que ha generado en numerosas comunidades y países de hablantes. Es lógico que los portavoces de esos dos billones de hablantes que componen "las otras lenguas de ingles" -atrapados a veces en las paradojas de la condición bilingüecuestionen persistentemente su relación con los herederos de la lengua materna. 
Como reconoció el novelista Chinua Acheve (1994:433) el precio que han tenido que pagar ha supuesto sumisión de distintos grados, una dependencia que ha girado en torno a la lengua como medio de intercambio internacional, pues sólo aceptando su función universal han sido capaces de dejar ver la realidad africana y captar el sentir de la experiencia propiamente autóctona.

El objetivo que insinuó este novelista dista mucho de otros más radicales a la hora de reclamar una lengua internacional que no muestre relación alguna entre el habla y la cultura, que no sea entendida como propiedad de un país específico, que sea puramente funcional, o cuyo aprendizaje no entrañe la internalización de normas culturales propias de la lengua madre. La pura enumeración de estas pretensiones suscita inevitablemente serias reservas. ¿Cómo separar lengua y cultura? ¿No es acaso la enseñanza de un modelo de inglés, de una norma lingüística, de una expresión verbal, de una equivalencia expresiva, de una variante morfológica o lexical un acto culturalmente significativo? ¿Cómo limitar la actividad de traducir a mero gesto intertextual culturalmente neutro? ¿Cómo reducir la enseñanza de la lengua a meras destrezas comunicativas?

Precisamente la aceptación y expansión del inglés como lengua de la globalización ha tenido que solventar su aplicación más servil e instrumental. Como ha advertido Martin A. Keyman (2004:10), si la propuesta del inglés como lengua franca ha tenido que liberarse de su herencia cultural nacionalista e imperialista, ¿significa esto que haya de desprenderse de la cultura? Obviamente la historia de la globalización ha conocido momentos en los que la revolución tecnológica hacía presentir una reducción de la lengua inglesa a medio tecnológico funcional, o como sugiere Martin A. Keyman (2004:10-13), al lenguaje por antonomasia de la tecnología, una funcionalidad que define todas las redes de la revolución de las comunicaciones. Pero los escenarios pedagógicos e interculturales de esta revolución han propiciado una revitalización del los factores culturales, todavía marcados y tensionados por las relaciones entre procesos de localización y de globalización. En los últimos años la incidencia del factor cultural y sus pretensiones políticas han acentuado su función rupturista dentro de esferas sociales poco marcadas por una identidad definida, o situados en los escenarios de la diáspora o de deterritorializados, alejados de los paradigmas nacionalistas determinados por la colonización. Es evidente, como observa Arjun Appadurai, que la deterritorialización crea mercados para compañías cinematográficas, empresarios del arte, agencias de viaje y otras actividades que nutren a la población necesitada de un vínculo estable con su comunidad, región o país (Appadurai 1996:38).

Es precisamente dentro de este territorio desde el que se proyectan las perspectivas transformadoras de la globalización. No podemos cerrar los ojos a la realidad y advertir cómo vivimos en un mundo multicultural que usa y precisa de otras lenguas para potenciar una comunicación eficaz y rica culturalmente. Los efectos de la globalización en este sentido han resultado claramente paradójicos: han contribuido a enriquecer las variedades del inglés y potenciar normativa y culturalmente algunas de ellas y, a la par, abrir el abanico de otras lenguas. Han multiplicado el intercambio de traducciones y sus circuitos internacionales, descubierto autores y popularizado otros, potenciado los recursos electrónicos y expandido las lenguas locales 
y sus culturas. Existe la sensación, precisa Ayo Bamgbose (2001:359), de que cuantas más divergencias haya dentro del inglés y más acusadas sean sus variedades culturales menos posibilidades tendrá de erigirse en lengua internacional. No sólo las diferencias dentro del inglés se han acentuado, sino que estas otras lenguas juegan un papel cada vez más relevante en los procesos de comunicación, sea por razones tecnológicas (Internet) económicas (transacciones, leyes del mercado), políticas o culturales. La multiplicación del repertorio de lenguas que reclaman una política lingüística autónoma es considerable en el contexto posmoderno. (Véase a este respecto la European Charter for Regional or Minority Languages y The Handbook of World Englishes, Kachru and Nelson 2006).

Desde esta realidad plural y globalizada el fenómeno de la traducción alcanza una relevancia crucial. Sin embargo su repercusión puede difuminarse por efectos tecnológicos. Una de las predicciones que desconcertaron a los lectores hace pocos años apareció hace pocos años (Mayo-Junio 2001) en The Futurist. En ella el periodista Sam Lehman-Wilzig predecía que la elaboración del sistema de comunicación universal y automatizada SATS preservaría la riqueza y belleza de la diversidad lingüística y cultural (Lehman 2001:2). Ni que decir tiene que no es la curiosidad científica lo que nos puede asombrar de este pronóstico, ni mucho menos qué pasará en el 2015, fecha en la que se supone que estará en marcha. Algunas de sus características técnicas ya las adelanta el propio Sam Lehman-Wilzig para satisfacción del lector: el sistema, basado en conexión inalámbrica mundial, se comunica, no con programas individuales, sino con interminables módulos de traducción. Así podrá traducir de forma especializada todas las lenguas del mundo (casi 6.000), facilitando la descarga de los módulos de cada una de ellas, como si de descarga de música se tratara. Y como la investigación en inteligencia artificial con redes neuronales hará posible la creación de programas inteligentes autodidactas y auto-correctores a gran velocidad, la automatización de la traducción conseguirá el fin alcanzar sus objetivos.

Las repercusiones de SATS preanuncian una fidelidad máxima en los procesos de transmisión y reproducción lingüística, por ahora objeto de ensoñación. El mundo de la política, por ejemplo, podrá evitar traspiés y manipulaciones que, como sabemos, tensan las crisis políticas, especialmente las más cruciales (recordemos las versiones interminables sobre los atentados del 11-S, o las de 4 de Marzo en Madrid, o los malentendidos lingüísticos que rodearon al juicio de Sadam). Las relaciones diplomáticas se verán sometidas a los filtros de transparencia e inmediatez que impidan las consabidas prácticas de ralentización o manipulación informativa, estratégica o decisoria. Los medios de comunicación tendrán que ajustar sus códigos éticos a la autenticidad o verdad nacida de la información instantánea. Y así en el ámbito de la comunicación y de la investigación científica, o en el del turismo, o en el de colaboración internacional en programas espaciales.

Que el futuro se hace presente con celeridad inimaginable forma parte del proceso perceptivo y fenomenológico cada vez más más apremiante. Ya nos encontramos dentro de un territorio globalizado en el que Internet nos ha colocado en el epicentro del espacio digital, permitiéndonos disponer de todos los medios de información al alcance. No sólo eso, la asimilación de los cambios que ha traído consigo la revolución digital ha generado nuevas funciones de mediación, traducción o inter- 
pretación lingüística y cultural que requieren contacto vivo con los movimientos de las lenguas y los textos, así como con los avances de las tecnologías multimedia.

Sam Lehman apunta en su pronóstico la paradoja más importante y consabida que viene produciendo el fenómeno de la globalización y que la mayoría de los expertos en ciencias de la comunicación, en antropología y en los estudios de traducción suelen reformular a su manera: que la globalización entraña riesgos de fragmentación lingüística y al mismo tiempo de integración, que por un lado puede limitar los procesos de mestizaje e hibridación lingüística y cultural y al mismo tiempo preservar muchas lenguas que están en procesos de extinción. Desde la óptica del mundo occidental, capitalizado por el dominio del inglés como lengua franca y de la cultura angloamericana como dominante, esta paradoja viene simplemente a significar que un sistema global y automatizado de traducción como el aquí proyectado puede terminar por consolidar esa lengua y esa cultura como centro ideológico mundial o diversificar otras lenguas y otras culturas. Es decir que su efecto puede ser centrípeto y centrífugo a la vez, re-integrador y fragmentador.

Esta paradoja ha recibido ya considerable atención por parte de especialistas en los estudios de política lingüística y de la traducción, unas veces impulsados por la vertiginosa marcha de la teorización y otras por la necesidad casi compulsiva de sospechar ideológicamente de las prácticas de traducción e interpretación. Anthony Pym (2003:7), por ejemplo, la reformula dentro del contexto económico más plausible. La paradoja, que él denomina "paradoja de la diversidad ", es explicable en función de las categorías económicas de producción y de distribución del mercado. No es igual producir traducciones, muy centralizadas internacionalmente, que distribuirlas, un proceso dependiente de contextos y ambientes de consumo locales. En este sentido, toda esta nueva geometría asimétrica entre lo uno y lo múltiple, como prefiere calificarla Anthony Pym, permite entrever que traducir al inglés es muy distinto de traducir del inglés, que entran en juego muchos factores de relaciones de poder, tanto en los procesos de producción como de distribución y que básicamente, aunque no enteramente, la geometría convencional entre lengua de partida y lengua de llegada resulta cuestionable. La traducción a las lenguas de producción, sugiere Anthony Pym, debe ser fundamentalmente distinta que la que procede de ellas, una asimetría ciertamente signficativa contra la que hay poco que hacer (Pym 2003:7).

El escenario que advierte Anthony Pym permitiría detectar y analizar multitud de situaciones, especialmente las que tienen que ver con la comunicación de la cultura popular, los medios audiovisuales, o la transmisión de naturaleza tecnológica o económica. No cabe duda que las transformaciones que pueden sufrir los textos a traducir dentro de estos procesos de adaptación o de confrontación entre las fuerzas de globalización y de localización pueden ser muchísimas. Infinitas, matizaría Susan Bassnet, si se trata de noticias diseminadas desde las redes globales de las agencias hasta los contextos locales. Forman las agencias de noticias, matiza Pablo García Suárez (2005:187) la "primera línea de combate" en la traducción de los nuevos términos que designan la nueva realidad y, obviamente, son las primeras en revelar cómo se resuelven los problemas de asimilación de determinadas culturas. De ahí su responsabilidad y su incidencia globalizadora. 
Situarse dentro de este escenario polarizado requiere tal vez, como señala Michael Cronin, el conocido autor de Translation and Globalization (2003) caer en la cuenta de que hay lugar para la iniciativa personal, pues, según él, las empresas se localizan en primer lugar para que los usuarios tengan sus propias preferencias de cara a la información y de manera que los sitios web produzcan sus propios lenguajes. Más aún, esta alternativa no parece mermar la cantidad de traducciones ni hacerla desparecer, pues simplemente transfiere la actividad traductora a quienes no hablan la lengua dominante, a quienes deben traducir desde fuera de ella y hacia ella. Resaltando aún más esta paradoja Cronin reconoce que: "The Universalist credo of localization is underwritten by a tension between the conflicting logics of technology and culture. There are approximately 6000 languages on the planet but only two systems of voltage, three railway gauges and one language for air traffic control. We might say that technology brings together what culture sets apart (Croning 2005:76)"

No es probable que muchos lectores acepten una confrontación tan tipificada entre tecnología y cultura como la que ofrece aquí Cronin, pues no es difícil intuir por dónde puede transcurrir el revulsivo ideológico. Pero sí es cierto que es fácil naufragar entre estos dos mares opuestos, si no se precisan con claridad las funciones de los procesos y productos traducidos, sujetos unas veces a los efectos universalizados de la globalización y otras a reacciones más específicas. Como el mismo Cronin advierte, dentro del marco global de la diseminación de productos y servicios, el acto mismo de traducir subraya la resistencia de lo específico frente a lo universal. Mary Snell-Hornby (1998:14-16), por ejemplo, que llega a condensar esta paradoja en dos emblemas sumamente polémicos de nuestros días, la Jihad frente a MacWorld, -uno encarnación de un fenómeno de re-tribalización culturalmente inquietante y otro epítome de un consumismo general y devastador, confeccionado "a la americana", tanto en su lenguaje y estilo como en sus pequeñas dosis de alimento intelectual rápido caprichosamente distribuido por Internet,-- advierte que es preciso aceptar alguna noción de identidad cultural válida que recree el sentido de colectividad, que despierte la conciencia de tener y compartir algo en común, algún rasgo auto-definidor de lo que se supone debe ser una comunidad. Entre los frentes y efectos opuestos de la globalización -universalización del mercado y tribalización- el supuesto de una identidad cultural permitiría situarse con acierto ante los otros y reforzar las bases colectivas de esa identidad.

Es sin duda en los procesos de localización donde la oposición tecnología-cultura suscita controversia, pues estos procesos no dejan entrever hasta qué punto protegen o afianzan las diferencias culturales o los elementos más específicos de las lenguas y culturas minoritarias. La sospecha de que esos procesos favorecen a los agentes y agencias de producción es enteramente fundada, pues la localización se usa casi exclusivamente por las grandes corporaciones americanas como vehículo para incrementar sus beneficios. En este sentido el término "a-localización" acuñado por Elena Castro, del Instituto de Gestión de la Innovación y del Conocimiento, capta con acierto esa percepción en el campo de la colaboración de empresas locales con otras de regiones más desarrolladas, por razones científicas o de investigación especializada. Por la lógica del propio mercado los productos suelen ajustar sus 
rasgos pragmáticos (fechas, direcciones, traducciones, medidas.) y estéticos (imágenes, colores, estilos) a las reglas de aceptabilidad comercial, en general en detrimento de sus contextos culturales, por no hablar de sus contenidos. Dentro de esta dinámica mercantilista la comunicación, que debiera ser parte de la misma cultura, queda relegada a un plano muy secundario o pierde sus marcadores culturales. De este modo la traducción se encuentra en este contexto culturalmente neutralizada, cual si se tratara de un mero producto u objeto estereotipado. Por el contrario, en casos de estrecha colaboración en proyectos entre dos empresas de dos países distintos el ingrediente cultural suele ser más importante de lo que pudiera parecer. Como es de presumir, si a nivel técnico la cultura no plantea problemas, en otros niveles sí puede ser un obstáculo importante pues las soluciones técnicas producen menos conflictos en trabajos de colaboración internacional que las de carácter cultural entre los dos países implicados en un proyecto. Ello nos lleva a movernos con cautela dentro de la polarización señalada y entrever cómo la traducción simultáneamente facilita la expansión de una economía global de la información, como sugiere Cronin, y a la par muestra signos de resistencia de las lenguas y culturas a una homogeneización tecnocrática.

La evolución de la crítica poscolonial y la apertura transnacional de estas alternativas suscitan interrogaciones más radicales que las que suelen confrontar estos dos frentes en un contexto economicista o tecnológico. Porque ¿ha de entenderse la traducción como un ejercicio culturalmente justificado frente al poder colonial dominante, aceptando la ecuación entre representación textual y experiencia histórica? ¿Hemos de aceptar que la traducción "traduce" efectivamente el lenguaje, la cultura o las diferencias ideológicas en clave transgresora, situada entre la resistencia a ese poder colonial y su apoyo o reproducción? ¿Se asienta la práctica de la traducción sobre las premisas que establecen una equivalencia entre procesos históricos y estructura textual, entre factores de "dominio simbólico" y estrategias de subyugación o discriminación? ¿Podemos seguir considerando la traducción como arma de sometimiento o control cultural? El sentido de estas preguntas insinúa una postura ideológica muy asumida por numerosos especialistas, especialmente asiáticos, conscientes de los riesgos de una repetición de los problemas generados por la globalización en el nuevo horizonte transnacional.

Recordemos que el post-colonialismo irrumpió en los estudios de traducción proyectando su eclecticismo teórico y una apertura interdisciplinar y sociocultural politizadas, cuya marca ideológica apareció registrada en obras de Homi Bhabha (The Location of Cultures,1994), Gayatri Spivak (In Other Worlds,1987-88), Lawrence Venuti (Rethinking Translation:Discourse,Subjectivity, Ideology (1992), Theo Hermans (The Manipulation of Literature:Studies in Literary Translation (1985) y en publicaciones señaladas de muchos otros especialistas, entre ellos Vicente L.Rafael, Tejaswini Niranjana, Douglas Robinson, EricCheyfitz, Lydia H.Lin, Frederick C. Schaffer y Lydia H. Liu. La atractiva perspectiva que vienen ofreciendo los fenómenos de la hibridación, la exploración de los contextos desde ángulos y fronteras contrapuestas, internas y externas, y la compleja actividad de transferencia cultural permiten tratar la traducción como acto de comunicación translingual y transcultural. El estudio de Vicente L. Rafael, por ejemplo, sobre las 
relaciones entre Castilla y el pueblo Tagalog de Filipinas, a partir de textos en ambas lenguas, concentra en el lenguaje de la conversión al catolicismo, la problemática ideológica de la traducción, desvelando los procesos de internalización de las convenciones cristianas, los efectos de la traducción de la gramática e impacto social y político.

Aflora en el estudio de Vicente L. Rafael la hipótesis tan recreada por traductores muy puristas de lo que tiene de intraducible la traducción, de que algunos términos religiosos tanto latinos o castellanos como en su acepción local tagalog, no logran captar plenamente la relación transcultural. Sería preciso recordar en este caso la densidad semántica de algunos términos religiosos, su iconicidad y dimensión simbólica, así como el de las funciones retóricas de los manuales de los misioneros para no circunscribir lo intraducible al poder de la colonización. La autora de Translingual Practice (1995) Lydia Liu, situó el problema de la inconmensurabilidad de la traducción precisamente como línea divisoria entre lo que se supone entienden los críticos sociales o culturales por diferencias, equivalencias, reciprocidad de culturas y de lenguas. Los espacios complejos de la hibridez, la criollización, el mestizaje cultural, o la liminalidad, pensamos, presentan direcciones a veces encontradas entre las perspectivas que ofrecen la globalización, el pos-colonialismo o las relaciones transnacionales y los ritmos de la realidad que acaban siendo ocupados por la decepción política, el resentimiento o la desconfianza crítica. Quedan para ensueño de la imaginación futurista la repetición febril de consignas y discursos interculturales. Justamente esta autora relata cómo las actuales relaciones de poder configuran la traducción de tal manera que es preciso calibrar la magnitud del sacrificio humano para poder apreciar la verdadera inconmensurabilidad de las palabras (Liu 1995:35).

Se comprende, por ello, que Naoki Sakai, por ejemplo, en Translation and Subjectivity: On Japan and Cultural Nationalism (1997) anhele concentrar en el acto de traducir una percepción de lo intraducible, no en función de las equivalencias o diferencias textuales, sino en razón del esfuerzo y de la posición enunciativa del traductor, de sus situaciones de habla, negociando subjetivamente una mediación entre emisor y receptor. La confusión posible que pueda aparecer entre la hibridez y la multiplicidad se despeja así subjetivamente, dejando de lado al hipotético "receptor" colectivo que remita a conceptos de identidad nacional o social .Los traductores, declara Ellen B. Basso (2002:189), se encuentran siempre inmersos dentro de sistemas culturales y de la historia, contextualizando sus conversaciones. $\mathrm{O}$, evocando una experiencia que corroborarían nuestros colegas de profesión, las mejores traducciones son aquellas que establecen conexiones imaginativas entre problemas, gentes y lugares diversos y ampliamente separados.

El marco transnacional que configuran estos casos no es el que dictaminan dos o más enclaves de producción de mercados, recursos o centros orientados por la competitividad profesional o las reglas de la negociación política. En aras de la clarificación ideológica pueden utilizarse miméticamente criterios comparativos y analógicos entre dos culturas o lenguas que desvirtúen el sentido de la comunicación transnacional. De forma cautelar advierten Robert Stam y Ella Shohat (2009:477), que las comparaciones transnacionales sirven para infinidad de propósitos. Aunque 
la observación no implique a traductores hipotéticos, los prejuicios culturales que reaparecen en estas comparaciones constituyen una premisa metodológica certera. Las comparaciones transnacionales, precisan estos dos especialistas, pueden revelar una negociación constante entre un universalismo fácil que niega la diferencia, una condena de la diferencia, un maximalismo diferenciador (No tenemos nada en común con ellos) frente a un paternalismo cercano al amiguismo (No tenemos nada en común, pero no olvides que eres un subordinado) e incluso hasta un desprecio casi masoquista (Nunca seremos tan buenos como vosotros). Las naciones, añaden estos dos críticos, pueden proyectar sus características más negativas sobre otros países que como su alter ego las perpetúan o reproducen. Lamentablemente no es este un problema de psicología social, ni de suspicacia transnacional, sino de política básicamente racial.

No procede, creemos, lanzar conjeturas sobre si las fronteras transnacionales van a deslizarse por sendas similares a las que vienen acompasando a la globalización. En principio la situación de confrontación que ha ido desarrollando la globalización no parece haber condicionado la producción cultural de centros y regiones que la engloban, que han trazado sus fronteras, captan su heterogeneidad o su adaptación a modelos culturales diferentes. Mas la movilidad de intelectuales, la concentración de información o la actualización de medios tecnológicos invita a sospechar sobre el verdadero sentido del diálogo transnacional. Al fin y al cabo, argumenta Micol Seigel (2005:66), si no existe una ecuación exacta entre signo y significado en un lugar, existe menos posibilidad y por lo tanto menos esperanza de que se exista equivalencia perfecta entre dos, o más, si la gente habla varias lenguas o si el observador adopta una perspectiva diferente. ¿Qué elementos, nos preguntamos, o factores harían transitable, pues, el territorio transnacional? ¿La emulación cultural, el intercambio, la reciprocidad intelectual, la afinidad o identidad racial, la interpelación social y política? En cuestiones tan controvertidas como la como la raza, el género o la clase social el ámbito transnacional requerirá unas pedagogías culturales decididamente diferenciadoras. No es preciso rememorar historias políticas y culturales de varios hemisferios para refrendar esta realidad, pues esas historias han diseñado la geografía transnacional del Caribe, Latinoamérica, África o Asia. Mientras Montreal, Ciudad del Cabo, Calcuta o Barcelona configuren alternativas lingüísticas cosmopolitas y al mismo tiempo diaspóricas, o haya en su hibridez cultural margen para una tercera lengua es de imaginar que las barreras transnacionales deberán ser realmente fluidas.

\section{Modalidades textuales y procedimientos críticos de signo transnacional}

Como puede apreciarse el escenario que anticipó Sam Lehman-Wilzig debiera despertar la curiosidad del traductor hacia esa nueva geografía cultural que permite transitar por las paradojas de la diversidad y atravesar fronteras transnacionales. Obviamente, nos recordó Anthony Pym, los modelos de localización no encuentran su anclaje en el centro del la cultura tradicional, ni poseen la autoridad de los producidos por ella, sino que suelen carecer de una autoridad cultural fuerte y por lo 
tanto constituyen el punto final de la secuencia comunicativa, pero permiten, no sólo advertir la complejidad de muchísimos encargos de traducción en cuanto actos de comunicación, sino también sopesar cómo reconfiguran culturalmente el proceso de la traducción.

Una aproximación a lo que viene sucediendo a este respecto aparece apuntada por Minako O'Hagan y David Ashworth en Translation-Mediated Comunication in a Digital World (2002) en el que postularon cómo el cambio de paradigma en los estudios de traducción nos aproximaría al esquema futurista presentado al principio y que ya opera entre numerosos medios de comunicación, la tele-traducción y tele-interpretación, la articulación interactiva de contextos no verbales, el desarrollo de los "chats" online mediante el uso de textos interactivos o la emigración de web-sites a pantallas de teléfonos móviles. Unos pasos más adelante, o una milla más, como ellos prefieren, espera el reto de crear desde un mundo virtual tridimensional algo que pueda sustituir a aquellas actividades exigidas por la presencia humana y que requieren una interacción cara a cara. No sólo eso, el verdadero reto de los medios de comunicación multimedia y multi-modales consistiría en facilitar la aproximación a la supuesta intención del significado del texto a través de la investigación de situaciones contextuales, es decir, a través de esos marcos o escenas que redefinen los sistemas de “opciones lingüísticas" según el lingüista Fillmore, cognitivas, pragmáticas o simplemente heurísticas según otros, y que son tan fundamentales en la investigación antropológica, sociológica y en los estudios de comunicación intercultural.

Como es bien conocido, el espacio intercultural de la traducción suele ser explorado a partir de esos marcos, movidos los especialistas por la necesidad de re-contextualizar todo el proceso de traducción y por la constatación de que la utilización de tipologías textuales o genéricas resultaba insuficiente, aunque sólo fuera para describirlo. Hemos vivido tan magnetizados por este artificio verbal que el salto a los medios digitales ha producido algo de vértigo. Esta percepción es tan general y ha suscitado tantas explicaciones desde tantas perspectivas (psicológica, filosófica, lingüística, antropológica) que huelga repetirlas. Sí convendría detenernos en algunas para entender la propia intrahistoria de la traducción, y sobre todo, lo que implica su enclave intercultural en nuestros días.

Relatar la apertura contextual del proceso de traducción entraña seguir las pistas desde aquellas posiciones que iniciaron el desbordamiento del campo textual apoyados en teorías funcionales, pragmáticas o sistémicas del texto hasta otras más amplias, como las inter-textuales, poli-sistémicas o culturales. Casi de forma obsesiva se nos dice que la traducción debe tener en cuenta todas las "posibles relaciones entre el texto de partida y toda una gama de textos potenciales de llegada" (Neubert \& Shreve (1992:14), o de que debe incluir conocimientos, sentimientos, intenciones, necesidades y expectativas del traductor. Hemos traducido conscientes de que el contexto no podía solamente esconderse en las afueras del texto de partida o evocado en el de llegada, como algo externo o superpuesto a ambos. Abundan los consejos en este sentido, mezclados con brillantes intuiciones sobre el carácter creativo del proceso traductor, el combate íntimo con el lenguaje, el esfuerzo afectivo, como diría Sandra Bermann (2009:440) que crean los ecos y sus protocolos e incluso, como aventura Venuti, hacer algo que justifique otra versión. 
El marco intercultural por el que transita la traducción debiera alentar estas posibilidades, por más que algunos especialistas se ciñan a esquemas precisos de la lingüística sistémica (Véase Julian. House 2005:350) y entiendan que un contexto cambiante dinámico y negociable no es viable para la traducción, como no lo sería una acepción de "cultura" concebida" en esos mismos términos. Y es aquí precisamente donde convendría precisar lo que se entiende por cultura y por qué las distintas formas de contextualizarse llegan a plantear verdaderos problemas al traductor de a pie. Pocos términos del mercadeo lingüístico internacional resultan hoy tan maltratado e intercambiable como el de "cultura"; todo un ejemplo de negociación arbitraria y re-contextualizada. Se recordará que hace ya mucho tiempo, allá por 1952, los antropólogos americanos Alfred Louis Kroeber y Clyde Kluckhohn, llegaron a compilar hasta 164 definiciones que con toda seguridad podrían aliviar los efectos dispersores de la globalización. También hace ya bastante tiempo que en el área de la traducción se viene hablando de transferencia intercultural, o de proceso intercultural, casi desde que Eugene A. Nida empezara a incorporar aspectos culturales en ella, o desde que la influencia de los antropólogos americanos Bronislaw Malinowski y Franz Boas, así como del lingüista Leonard Bloomfield, se dejaran notar en la consideración de los contextos situacionales elaborados por los lingüistas ingleses J. R. Firth y Halliday. Posteriormente, y como si los elementos culturales fueran piezas de un rompecabezas, algunos lingüistas han hablado de "focos culturales" (Newmark (1988/92), de "realia", referencias culturales o "culturemas".

Pero, aunque la simbiosis entre antropología y lingüística -recordemos el impacto de las tesis de Sapir-Whorf en los modelos sistémicos- fue importante para comprender la función de la cultura en la traducción, sería la incursión de los estudios culturales en este panorama -así como de otras tendencias o escuelas afines tales como la poli-sistémica o la llamada escuela de la manipulación- los que abrirían radicalmente su espacio intercultural. A pesar de las numerosas reservas que han suscitado, de su decepcionante pedagogía, de su arbitraria filosofía y de su oportunista politización, lo cierto es que han ayudado a repensar el fenómeno de la traducción desde ángulos y contextos muy diversos. Baste mencionar que metodológicamente no pretenden atenerse a criterios de equivalencia entre texto original y texto meta, sino superar el paradigma lingüístico textual, al entender que el proceso entraña una negociación compleja entre dos culturas. Las traducciones pueden ofrecer toda una serie de elementos que las convierten, efectivamente, como recuerda Susan Bassnett, en una actividad doblemente contextualizada, en un rastreo de las pistas que trazan los textos al convertirse en capital intercultural: convenciones de la cultura de destino, por ejemplo, mundo social del traductor, preferencias estéticas, sistemas de publicación, factores económicos, tradiciones literarias, función de las revistas y sus recensiones. Este trazado parece tan evidente que J. Lambert (1994:23) llamó la atención sobre el hecho de que se hubiera desconsiderado sistemáticamente y no se reparara en el papel del marco institucional del proceso, o de cómo operan las traducciones históricamente, por lo que se hacía necesario un acercamiento interdisciplinar.

A este respecto, y a modo de inciso, debieran mencionarse las "políticas traductoras" que han presidido la traducción de los grandes escritores latinoamericanos, en 
especial los más identificados con el llamado "Boom", pues tanto los mecanismos del poder como la voluntad del traductor para afirmar su independencia e introducir en la traducción cuestiones de interpretación, muestran a las claras cómo operan los frentes institucionales del proceso. La suerte de los grandes escritores latinoamericanos en el mercado anglo-americano, en especial Julio Cortázar, García Márquez, Vargas Llosa y Carlos Fuentes habla por sí misma. Aunque hoy en día su éxito y el de otros escritores -José Lezama Lima, Miguel Ángel Asturias, Alejo Carpentier, Octavio Paz, Augusto Roa Bastos, Jorge Amado, Manuel Puig, Severo Sardui, Elías Caneti, José Donoso- hacen olvidar las dificultades de salir adelante en ese mundo editorial, lo cierto es que resulta irónico, como lo ha delatado Payne, que el aumento de consumo cultural de los sesenta promoviera tan sólo el grupito de grandes escritores, que recreara una imagen estereotipada de Latinoamérica y que la labor de los traductores pasara desapercibida. Tal vez, entraron en juego varios factores, como sugirió Jeremy Munday en The Translation of Spanish American Literature: An Inevitable cultural distortion (2004): el hecho, por ejemplo, de que una misma persona, Gregory Rabasa , tradujera a varios autores, la política comercial selectiva de las grandes casas editoriales, y, por extraño que parezca, y como consecuencia de la influencia de la cultura latina en América del Norte, una confusión con respecto a la identidad del original y su autoría. Paradojas de la apropiación cultural, diríamos. $\mathrm{O}$ efectos de unas traducciones espléndidas. Espejismo similar ha acompañado la americanización de Borges. Para traductores tan independientes como Edith Grossman, Suzanne Jill Levine, Margaret Sayes Peden, Eliot Weinberger, o Daniel Balderston, Thomas Christensen, Catherine Silver o Evelyn Picon Garfield, estas barreras han generado una actitud de resistencia firme para abrir las compuertas de una política imperialista, restrictiva e insular, todavía visible en algunas editoriales. Como revelan las colecciones de The Subversive Scribe: Translating Latin American Fiction, 1991, editada por Suzanne Hill Levine, Translating Latin American: Culture as Text, editado por William Luis y Julio Rodríguez-Luis (1991, o las más recientes de Daniel Balderston y Mary Schwartz, o la de Efraín Kristal, Invisible Work:Borges and Translation (2002), la fascinación por el arte de traducir va unida a una función interpretativa de la cultura.

Este énfasis en las exigencias de la política cultural presupone que aunque la incidencia del este giro haya producido desconcierto en cuanto a concepciones teóricas aplicadas durante varias décadas o a ciertas prácticas de cuño estructuralista y pragmático, su alcance ha sido decisivo. De la evaluación crítica de las traducciones se ha pasado, como puede inferirse, a la consideración de los procesos complejos que comprende la producción textual. Lydia H. Liu en Tokens of Exchange: The Problem of Translation in Globall Circulation (1999) propone examinar la cuestión de equivalencias sugiriendo que son invenciones provisionales que gradualmente adquieren carta de hipótesis asentadas, por lo que convendría hablar de tropos de equivalencia, incluido el de la metaforización del acto de traducir, una propuesta ciertamente abierta a la textualización genérica, cultural y retórica. La introducción de esta perspectiva a ámbitos postcoloniales en Translingual Practice: Literature, National Culture and Translated Modernity, China 1900-1937, (1995) fue confiriendo entidad a la función histórica, social y política de la elaboración del tropo. La 
creación cultural en este marco posibilita equivalencias entre "traducción" y "transnación", articulando de hecho un verdadero proceso de "translación cultural", un concepto y estrategia analítica similar al de "canibalización" que aplicara Haroldo Campos en Brasil. Es atractiva, sin duda alguna, la sustitución terminológica de "source" y "target", por "host" y "guest", polos de una transacción casi siempre entrañable, por tensa que resulte.

Consideraciones de este tipo invitan a advertir cómo la traducción encaja en un escenario propiamente transnacional, al fin y al cabo expresión cabal de la globalización, pues el desbordamiento de fronteras textuales ha dado paso al universo discursivo que ofrece el cruce de culturas, su interrelación, sus diferencias o mestizaje. Como ha observado Appadurai (1966), la diáspora y sus diversas esferas públicas acrisolan un nuevo orden político postnacional, espoleado por una movilización consciente de las diferencias culturales, la influencia de los medios de comunicación, el consumismo de masas y la tecnología. Ello implica una nueva política identitaria que, como es sabido, estaría articulada por un imaginario social en constante readaptación y elaboración como respuesta a nuevos contextos locales, factores políticos y sociales, así como discursos culturales transnacionales. Y su complejidad, como la historia reciente viene mostrando en África, Brasil, el Caribe o los Estados Unidos, presenta grietas abiertas que difícilmente configurarán una geopolítica transnacional basada en criterios comparatistas.

Muchos expertos en traducción descartan abiertamente en este empeño la influencia los estudios culturales por considerar que tan solo se trata de tener en cuenta aspectos sociales y políticos de este fenómeno, por carecer aquéllos de metodología para abordar problemas concretos o de presentar la cultura como algo tan fluido y cambiante que resulta intraducible.

Pero muchos otros especialistas recurren a los estudios culturales para saldar cuentas con las diferencias aún evidentes entre el Norte globalizado y el Sur globalizado, para observar cómo la fluidez de los procesos de traducción entre estos dominios continúa dependiendo de un mercado cultural mono-lingüístico, o para examinar qué textos literarios son elegidos para su publicación, o qué instituciones editoriales o académicas condicionan estas transacciones culturales. No está de sobra recordar que el marco transnacional o los mecanismos de relación transnacional vienen determinados por una motivación cultural y actitud hacia el "Otro", o todo lo que este término conlleva, decididamente rubricada por una política de colaboración, inclusión y contraste críticos. Como Emily Apter matizó en su "Translation/Transnation", introduciendo Translation Zone: A New Comparative Literature (2006), la topografía intelectual de este proceso no es propiedad de un sólo país ni una condición amorfa asociada con el postnacionalismo. La raíz común entre ambos términos, añade Emily Apter, -trans - sirve como puerto de traslado y comunicación entre pequeñas comunidades lingüísticas o países, y como cesura cultural - a trans-ation- que recoge los fallos de transmisión. Cualquier mapa cultural de estas translaciones reflejaría sin duda los efectos políticos y culturales de los estudios culturales, o al menos la necesidad de una pedagogía de la traducción que ofreciera pruebas evidentes, como las reclama Gayatri Spivak (1990:79), de que el descentramiento del imperio lingüístico del inglés es posible. 
No es una simple conjetura advertir cómo la instrumentalización ideológica de la traducción aparece nuevamente entre estos horizontes transculturales, justificada unas veces por metodologías comparativistas y otras por las pretensiones científicas que espolean las diferencias culturales, la diversidad de formas literarias, la diseminación cultural, la teoría o los medios tecnológicos. En la actualidad la práctica de la traducción literaria ha prestado servicios importantes a las políticas transnacionales de la literatura comparada y a los estudios norteamericanos, a la primera en base a sus métodos de lectura e interpretación y a la segunda impelida por su poder cultural internacional, su expansión politizada y su historia multicultural. Desde estos dos horizontes la traducción actúa como intermediaria insustituible entre varias lenguas y culturas, dejando ver cómo el interés por la textualidad híbrida que ha acompañado el acercamiento a las relaciones o diferencias multiculturales viene trasladándose al estudio de textos contrastados, homologables, analógicos, o divergentes. De manera a veces ciega el traductor se entrega a la detección de calcos culturales, préstamos, ejemplos de trasposiciones, dobletes y referencias concretas en el texto sin tener en cuenta aquellos aspectos de producción y de recepción del texto que pueden iluminar precisamente esos mismos elementos. Ello da que sospechar sobre el alcance de lo que denominamos traducción intercultural, en muchas ocasiones concebidas como interculturales cuando no lo son. Tal vez conjugan aspectos culturales de dos lenguas contrapuestas, residuo de la vieja concepción de la cultura en la traducción como algo extralingüístico, enciclopédico o extratextual. Es crucial, nos recuerda Shi-xu en Critical Pedagogy and Intercultural Communication (2011), que caigamos en la cuenta de que las acciones discursivas en un proceso de comunicación intercultural no están sólo para ser comprendidas sino, evocando a Gadamer, para ser interpretadas y apropiadas (285) y que estas funciones se llevan a cabo en un contexto de relaciones de poder. Que nadie nos engañe, advierte Jose Yuste Frías en "Desconstrucción, traducción y para-traducción en la era digital". "La traducción es siempre confrontación, diálogo con el otro y no su asimilación, su integración o su rechazo....la traducción ha sido, es y será siempre hibridación, permeabilidad, contraste y emulación de otro: movilidad y mestizaje....la tarea del traductor es también la de recordar a los lectores de una lengua dada que es posible vivir, pensar y expresar el mundo de otra forma (Yuste2000:69).

Ni que decir tiene que el espacio demarcado por José Yuste para los procesos de hibridación es amplio y obliga a agudizar el sentido relacional del traductor. Traducir, efectivamente, es un acto interpretativo y aunque se asemeja a la co-creación, o "colaboración íntima" como le gustaría decir a Cabrera Infante, lo que le interesa al traductor, afirmaría Suzanne Jill Levine, es conocer al otro y descubrirse a sí mismo, razón primera y última, diríamos, de toda relación o transacción humana. La insistencia en la autenticidad del acto traductor resuena cada vez que asoma la posibilidad de su instrumentalización. Y es evidente que en los últimas décadas años el fenómenos de la hibridación textual, sin duda espoleada por las corrientes más críticas del pos-colonialismo, ocupa uno de los espacios más codiciados de ese escenario intercultural y transnacional, sin duda alguna como frontera paradigmática de su función cultural e ideológica. Aunque este segundo motivo parece convertir los estudios de traducción en una especie de laboratorio experimental para otros fines 
más especulativos, -y no todos estarían de acuerdo en admitir la "hibridación" como arma eficaz para resistir los efectos de la globalización- lo cierto es que se ha llevado a cabo una revisión amplia de numerosas obras y textos que expresan o tipifican las posibilidades de la traducción intercultural. De hecho podría aceptarse la hibridación como metáfora explicativa de la traducción; y si nos salimos del campo poscolonial extenderla incluso a todo el proceso de globalización. Es evidente que vivimos varias culturas simultáneamente, que hay diversos grados de contacto entre ellas, -desde una mera coexistencia hasta su transformación sustancial, pasando por la negociación o interacción dinámica,- y que la hibridación abre expectativas innovadoras frente al dominio de culturas monolíticas.

Desde el enclave poscolonial la hibridación textual ejerce un atractivo crítico importante, expresivo y resultado de su construcción social y política, como espacio tensado por la interacción entre dos culturas formulado por oposición dialéctica entre ellas en cuanto: zona de contacto (Mary Louis Pratt), life in the hyphen (Gustavo Peret Firmat), borderlands (Gloria Anzaldúa),canibalización (RobertoFernández Retama) o “transculturación”(Fernando Ortiz). Como sugiere Ovidi Carbonell (1997:114) la hibridación no sólo resulta inevitable sino que puede llegar a ser muy positiva. Pone en juego, obviamente, toda una "serie de tensiones que posibilitan la producción del significado ajeno en la cultura de destino", como podemos percibirlo si examinamos los factores de recepción a través del papel del traductor, el editor o el lector de un texto. Cuando Schäffner y Adab (1997) acuñaron el término "texto híbrido" ya lo advirtieron al comprobar cómo algunos textos contienen elementos que chocan con la lengua meta, con su cultura y sus convenciones culturales, muy patentes en la incrustación textual de jergas, modismos o coloquialismos que son simplemente producto natural de un mundo globalizado. Al lector de la literatura chicana, por ejemplo, le resultan familiares esas intersecciones que Gloria Anzaldúa, Guillermo Gómez Peña, Alberto Kurapel, Cristina García, Simón Ortiz, y en general todas las "Hijas de la Malinche" crean y habitan literaria y culturalmente. No es concebible revivir un proceso cultural tan revestido por la traducción como el chicano..

Mas la textualización de la hibridez cultural viene hallando en territorios transnacionales alternativas enriquecedoras, por asimétricas que resulten. El encanto de la ideología, o una curiosidad compulsiva por explorar esos textos desde todos los ángulos posibles crearon en torno a la hibridación el enclave predilecto de este espacio intercultural, Desde él puede abordarse la transferencia cultural al texto, manifestar cierta resistencia a los procesos de globalización, postular una razón epistemológica convincente al hecho de la traducción y participar en el proyecto revisionista que han emprendido críticos reconocidos, entre ellos A. Lefevere, A. Niranjana, G.Spivak, L .Venuti, A. Berman, Haroldo Campos. Trátese de examinar los efectos de domesticación o extranjerización que revelan los textos, de auscultar la documentación requerida para realizar esas prácticas, de constatar aspectos concretos de su producción o recepción o simplemente de contrastarlos lingüística y retóricamente, lo que auspician estos procedimientos no es otra cosa que reconocer el sentido de la traducción a través de la historia y situarla precisamente en el espacio intercultural actual: el de una hibridación activa, como elemento de transacción cultural que espolea las relaciones de poder asimétricas actualmente operativas. Puede 
ser, como dice Susan Bassnett, que hablar de traducción poscolonial resulte tautológico, pues en este contexto de exilio, diáspora y emigración la etimología de la palabra "traducción" cobra su pleno sentido como traslado físico y traslación.

Puede celebrarse la tautología si al divisar el mapa transnacional advertimos que no se proyecta exclusivamente sobre el futuro, sino que ha recuperado el trazado transcultural del pasado, de la historia de la traducción, de la formación de las literaturas nacionales, de la historia de la escritura, de la literatura comparada, de la historia literaria occidental. ¿Nos extraña el hecho de que la única identidad autorial de la traducción en el siglo XVIII fuera la personalidad del autor? ¿Hemos constatado cómo Edward Young llegó a ocultar la fuente del valor de la traducción hasta relegarla al territorio del "Otro"? ¿Por qué los lectores de Thomas Wharton encontraron problemática la cuestión del estilo? Y, ¿dónde residió el éxito de la novela epistolar del XVII y XIX ingleses? ¿Qué idea de nación mantuvo viva la llama de su identidad? A tenor del escrutinio histórico y cultural del The Oxford History of Literary Translation in English (OHLTE)(2008) los tropos más eficaces de la expansión cultural británica recrean su fecundidad en terrenos abonados por la transfusión de prácticas, fronteras y movimientos interculturales, transacción de lenguajes y la alquimia de la influencia.

\section{Referencias bibliográficas}

Appadurai, A., Modernity at Large: Cultural Dimensions of Globalization. University of Minnesota Press 1996.

Apter, E., Translation Zone: A New Comparative Literature. Princeton University Press 2006.

BAmgBose, A., «Torn between the Norms Innovations in World Englishes», World Englishes 17 (1998), 1-14.

BamgBose, A., «World Englishes and Globalization», World Englishes 20, 3 (2001), 357363.

Bassnet, S., Translation Studies. Londres: Routledge 2006.

BAssnet, S. / Lefevere, A., Constructing Cultures: Essays on Literary Translation. Clevedon: Multilingual Matters 1998.

BAsso, Ellen B., «The Neologistic Imagination. A Review of Some Recent Books on Translation», Reviews in Anthropology 31 (2002), 185-197.

Bermann, S., «Working in the And Zone: Comparative Literature and Translation» Comparative Literature 61, 4 (2009), 432-446.

BIELSA, E., «Translation in Global News Agencies», Target: International Journal on Translation Studies 19, 1 (2007), 135-155.

Blommaert, J., «Commentary: a sociolinguistics of globalization», Journal of Sociolinguistics 4, 4 (2003), 607-623.

Canagarajah, A.S., Resisting Linguistic Imperialism in English Teaching. Oxford: Oxford University Press 1999.

Carbonell i Cortés, O., Traducir al Otro. Universidad Castilla la Mancha 1997.

Cheyfitz, E., The Poetics of Imperialism: Translation and Colonization from The Tempest to Tarzan. New York: Oxford University Press 1991.

CRONIn, M., Translation and Globalisation. Londres: Routledge 2003. 
Cronin, M., «Burning the House Down: Translation in a Global Setting», Language and Intercultural Communication 5, 2 (2005), 108-119.

CRYSTAL, D., English as a Global Language (2nd ed.). Cambridge: Cambridge University Press 2003.

Damrosch, D., How to Read World Literature. Chichester: Wiley-Blackwell 2009.

DERRIDA, J., «What is a Relevant Translation?». Trans. Lawrence Venuti. Critical Inquiry 27 (2001), 174-200.

DEweY, M., «English as a Lingua Franca and Globalization: an Interconnected Perspective», International Journal of Applied Linguistics 17, 3 (2007), 332-354.

GAmsA, M., "Cultural Translation and the Transnational Circulation of Books», Journal of World History 22, 3 (2011), 553-575.

GARCía SuÁreZ, P., «Noticias de agencia: Algunos problemas planteados en la traducción español-árabe», en: Cortés Zaborras, C. / Hernández NAVArro, Ma J. (eds.), La Traducción periodística. Cuenca: Ediciones de la Universidad de Castilla-La Mancha 2005, 175-197.

Goodson, I. / Medway, P. (eds), Bringing English to Order. Londres: The Falmer Press 1990, 1-47.

GradDol, D., English Next:Why Global English May Mean the End of "English as a Foreign Language”. Londres: British Council 2006.

House, J., «English as a Lingua Franca: A Threat to Multilingualism?», Journal of Sociolinguistics. 7, 4 (2003), 556-578.

House, J., «Text and Context in Translation», Journal of Pragmatics 38 (2005), 338-358.

Howland, D., «The Predicament of Ideas in Culture: Translation and Historiography», History and Theory 42 (2003), 45-60.

JAMES, A., «Theorising English and Globalisation: Semiodiversity and Linguistic Structure in Global English, World Englishes and Lingua Franca English», Journal of Applied Language Studies 3, (2001), 79-92.

JAY, P., «Beyond Discipline? Globalization and the Future of English», PMLA 16, 1 (2001), $32-47$.

JENKINS, J., «English as a Lingua Franca: Interpretations and Attitudes», World Englishes 28, 2 (2001), 200-207.

Kachru, B. B., Asian Englishes: Beyond the Canon. Hong Kong Sar, China: University of Hong Kong Press 2005.

Kayman, M. A., «The State of English as a Global Language: Communicating Culture», Textual Practice (2004), http://www.tandf.co.uk./journals.

LAMBERT, J., «In Quest of Literary World Maps», en Kittel, H. \& Frank, A. P. (eds.), Interculturality and the Historical Study of Translation. Berlin: Erich Schmidt Verlag, 1991.

LeHMAN-Wilzig, S., «Babbling Our Way to a New Babel: Erasing the Language Barriers», The Futurist. Mayo-Junio (2001).

Morgan, R., «The "Englishness" of English Teaching», en: Goodson, I. / Medway, P. (eds.), Bringing English to Order. Londres: The Falmer Press 1990, 197-241.

Parakrama, A., Dehegemonizing Language Standards. Learning from (post)Colonial Englishes about English. Houndmills, England: Macmillan 1995.

PenNyCOOK, A., The Cultural Politics of English as an International Language. Harlow: Longman 1994.

PHILliPSON, R., Linguistic Imperialism, Oxford University Press 1992.

Phillipson, R., «Linguistic Imperialism: a Conspiracy, or a Conspiracy of Silence?», Language Policy 6 (2007), 377-383.

Phillipson, R., «Lingua Franca or Lingua Frankensteinia? English in European Integration and Globalisation», World Englishes 27, 2 (2008), 250-284. 
PyM, A., «Globalization and the Politics of Translation Studies». Paper delivered to the conference Translation and Globalization (Canadian Association of Translation Studies) in Halifax, Canada 2003.

PyM, A., Method in Translation History, Manchester: St Jerome 1998.

PyM, A., The Moving Text, Amsterdam: John Benjamins 2004.

Rodríguez GarcíA, J. M. , «Literary into Cultural Translation», Diacritic 3, 3-4 (2004), 3-30.

Ross, T., «Translation and the Canonical Text», Studies in the Literary Imagination 33, 2 (2000), 1-21.

SCHÄFFner, C., «Political Discourse Analysis from the point of view of Translation Studies», Journal of Language and Politics. 3,1 (2004), 117-149.

Seidlhofer, B., / Breiteneder, A. / Pitzl, M. L., «English as a Lingua Franca in Europe: Challenges for Applied Linguistic», Annual Review of Applied Linguistics 26 (2006), 3-34.

SeIgel, M., «Beyond Compare: Comparative Method after the Trans-national Turn», Radical History Review 91 (2005), 62-90.

SNELL-HornBy, M., «Communicating in the Global Village: On Language Translation and Cultural Identity», en: SCHÄFFnER, C. (ed.), Translation in the Global Village. Clevendon: Multilingual Matters 2000, 11-28.

SPIVAK, G. C., «Reflections on Cultural Studies in the Post-Colonial Conjuncture», Critical Studies 3, 1-2 (1991), 63-78.

StAm, R. / ShohAt, E., «Transnationalizing Comparison: The Uses and Abuses of Cross-Cultural Analogy», New Literary History 40 (200), 473-499.

Venuti, L. The Translator's Invisibility: A History of Translation. Londres: Routledge 1995.

Vogeley, N., «Translation Studies: The Novel and Other Enlightenment Crossings», Eighteenth Century Studies 44, 2 (2011), 292-298.

WARren, M. R., «Translating English Literary History», Journal of English and Germanic Philology 110, 4, (2011), 489-515.

YUSTE FRÍAS, J., «Desconstrucción, traducción y paratraducción en la era digital», en: YUSTE FríAs, J. / Álvarez Logrís, A. (eds.), Estudios sobre traducción: teoría, didáctica, profesión. Vigo: Universidad de Vigo 2005, 59-76. 